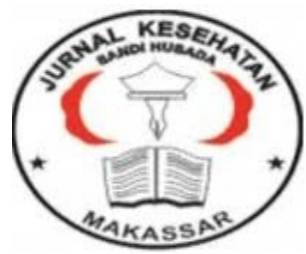

\author{
Jurnal Ilmiah Kesehatan Sandi Husada \\ hhttps://akper-sandikarsa.e-journal.id/JIKSH \\ Vol 11, No, 1, Juni 2020, pp;372-378 \\ p-ISSN: 2354-6093 dan e-ISSN: 2654-4563 \\ DOI: $10.35816 /$ jiskh.v10i2.299
}

\title{
Pengaruh Pendidikan Kesehatan Tentang Perawatan Pasien Stroke di Rumah Terhadap Tingkat Pengetahuan Keluarga
}

The Effects of Health Education about the Care of Stroke Patients at Home Against the Level of Family Knowledge

\section{Asrijal Bakri' ${ }^{1}$, Fransisco Irwandy ${ }^{2}$, Elmiana Bongga Linggi ${ }^{3}$ ${ }^{123}$ Sekolah Tinggi Ilmu Kesehatan Stella Maris}

\section{Artikel info \\ Artikel history:}

Received; 20 April 2020

Revised: 28 April 2020

Accepted; 05Mei 2020

\begin{abstract}
Abstrak
Pengetahuan merupakan segala sesuatu yang diketahui berdasarkan hasil penginderaan dan pengalaman yang didapatkan manusia. Perawatan penderita stroke di rumah oleh keluarga merupakan segala tindakan yang dilakukan keluarga demi mempertahankan kesehatan penderita stroke, seperti membantu aktifitas fisik setelah stroke, menangani kebersihan diri, menangani masalah makan dan minum, kepatuhan program pengobatan di rumah. Penelitian ini bertujuan mengetahui pengaruh pendidikan kesehatan tentang perawatan pasien stroke di rumah terhadap tingkat pengetahuan keluarga. Jenis penelitian ini adalah penelitian pre eksperimen, dengan pendekatan One Group Pre-test - Post-test Design. Populasi penelitian ini adalah keluarga pasien stroke yang berada di Poliklinik Neurologi Rumah Sakit Stella Maris Makassar. Pengambilan sampel menggunakan teknik nonprobability sampling, dengan pendekatan consecutive sampling. Jumlah sampel penelitian ini sebanyak 60 responden dan pengumpulan data dilakukan dengan menggunakan lembar kuesioner. Uji statistik yang digunakan adalah uji wilcoxon untuk mengetahui pengaruh pendidikan kesehatan tentang perawatan pasien stroke di rumah terhadap tingkat pengetahuan keluarga dan diperoleh nilai $p=0,000$. Berdasarkan uji statistik tersebut diketahui nilai $p<\alpha(0,05)$, maka dapat disimpulkan hipotesis nol (Ho) ditolak dan hipotesis alternatif (Ha) diterima artinya ada pengaruh pendidikan kesehatan tentang perawatan pasien stroke di rumah terhadap tingkat pengetahuan keluarga. Oleh sebab itu, perawat penting memberikan pendidikan kesehatan tentang perawatan pasien stroke dirumah pada keluarga agar pengetahuan keluarga meningkat.
\end{abstract}

\begin{abstract}
Abstrack
Knowledge is everything that is known based on the results of sensing and experience gained by humans. Care of stroke patients at home by the family is all actions taken by the family in order to maintain the health of stroke sufferers, such as assisting in
\end{abstract}


physical activities after a stroke, dealing with personal hygiene, dealing with eating and drinking problems, compliance with treatment programs at home. This study aims to determine the effect of health education about the care of stroke patients at home on the level of family knowledge. This type of research is a pre-experimental research, with the One Group Pre-test - Post-test Design approach. The population of this study is the families of stroke patients who are in the Neurology Polyclinic in Stella Maris Hospital Makassar. Sampling uses nonprobability sampling technique, with consecutive sampling approach. The number of samples of this study were 60 respondents and data collection was carried out using a questionnaire sheet. The statistical test used was the Wilcoxon test to determine the effect of health education about the care of stroke patients at home on the level of family knowledge and the value of $p=0,000$ was obtained. Based on these statistical tests it is known that the value of $p<\alpha(0.05)$, it can be concluded that the null hypothesis ( $\mathrm{Ho}$ ) is rejected and the alternative hypothesis ( $\mathrm{Ha}$ ) is accepted, meaning that there is an influence of health education about the care of stroke patients at home on the level of family knowledge. Therefore, nurses are important to provide health education about the care of stroke patients at home to the family so that family knowledge is increasing.

Keywords:

Pendidkan Kesehatan;

Pengetahuan;

Perawatan pasien

stroke;
Coresponden author:

Email: ijal.nusja@gmail.com

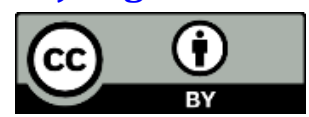

artikel dengan akses terbuka dibawah lisensi CC BY -4.0

\section{Pendahuluan}

Paradigma sehat sebagai suatu gerakan nasional dalam rangka pembangunan kesehatan menuju Indonesia sehat 2015 merupakan upaya meningkatkan kesehatan bangsa yang bersifat proaktif. Salah satu sikap proaktif ditunjukkan melalui mengatur perilaku hidup sehat dan seimbang. Sejumlah perilaku seperti mengonsumsi makanan siap saji (fast food) yang mengandung kadar lemak jenuh tinggi, merokok, dan minuman beralkohol, telah menjadi gaya hidup manusia terutama di perkotaan. Semua perilaku tersebut merupakan faktor-faktor penyebab penyakit berbahaya seperti jantung dan stroke (Dewi, 2010).

Stroke merupakan sindrome neurologi yang dapat menyebabkan kematian ataupun kecatatan fisik dan mental bahkan kematian dini pada stroke akut biasanya karena komplikasi neurologi disebabkan kompresi batang otak. Perubahan pada stadium awal stroke sangat penting untuk diketahui faktor-faktor yang berperan dalam kerusakan sel pada detik pertama kejadian stroke. Hal ini penting dilakukan untuk melakukan intervensi diri yang diharapkan dapat meningkatkan penyembuhan, kualitas hidup penderita, mempersingkat waktu rawat di rumah sakit dan mencegah tingginya kematian akibat stroke. (Misback, 2011 \& .Junaidi, 2011)

Menurut WHO (World Health Organization ), 2010 terdapat 15 juta orang yang mengalami stroke setiap tahun dan merupakan penyebab kematian kedua diatas 60 tahun dan penyebab kelima usia 15-59 tahun. Setiap tahun hampir 6 juta orang meninggal karena 
menderita penyakit stoke. (Munawwara, 2011). Sedangkan Jumlah penderita stroke di Indonesia dari tahun 2007 sampai dengan 2013 mencapai (8,3\%) per 1000 populasi (Riskesdas,2013)

Prevelansi stroke Sulawesi Selatan pada tahun 2013 merupakan yang paling tertinggi diantara semua provinsi-provinsi di indonesia dengan jumlah $(17,9 \%)$ per 1000 penduduk (Riskesdas, 2013). Sedangkan data prevalensi stroke Rumah Sakit Stella Maris Makassar pada tahun 2013 mencapai 314 (2,1\%) angka tersebut meningkat menjadi 339 $(1,6 \%)$ dari 21.277 pasien sedangkan data terbaru pada tahun 2015 menunjukkan penurunan menjadi 235 (1,3\%) dari 18.066 pasien. (Rekam Medik Rumah Sakit Stella Maris Makassar, 2015)

Kejadian stroke tidak hanya menimpa penderitanya melainkan juga mempengaruhi kehidupan keluarga. Salah seorang anggota keluarga mendadak menjadi tidak berdaya, menghilang perannya di keluarga dan menjadi beban keluarga. Ketika pasien stroke di rawat di rumah sakit, keluarga yang menjaga pasien stroke di rumah sakit jarang diberikan penyuluhan oleh perawat tentang bagaimanan merawat pasien stroke di rumah. Keadaaan ini menyebabkan sebagian besar anggota keluarga yang menemani pasien selama rawat inap hanya menerima informasi yang sedikit tentang bagaimana membantu keluarga mereka dan sebagai hasilnya mereka tidak cukup terlatih, kurang informasi dan merasa tidak puas dengan dukungan yang tersedia setelah mereka keluar dari rumah sakit Situasi ini akan menyulitkan apabila hanya ada satu anggota keluarga yang mampu merawat penderita stroke sehingga peran perawat sebagai edukator sangat dibutuhkan dalam memberikan pendidikan kesehatan tentang perawatan pasien stroke pada keluarga pasien selama proses rawat inap di rumah sakit (Ratnasari, 2014).

Pendidikan kesehatan merupakan proses perubahan perilaku secara terencana pada diri individu, kelompok atau masyarakat untuk dapat lebih mandiri dalam mencapai hidup sehat dengan mengubah perilaku yang tidak sehat atau belum sehat menjadi perilaku sehat. Dalam memberikan pendidikan kesehatan perawat harus memilih teknik pendidikan kesehatan yang tepat agar pasien ataupun keluarga mampu mendapat informasi dengan benar, oleh karena itu pendidikan kesehatan yang dilakukan dalam penelitian ini adalah menggunakan metode penyuluhan dimana metode penyuluhan khususnya perorangan sangat efektif karena sasaran dapat langsung memecahkan masalahnya dengan bimbingan khusus dari penyuluh. Penyuluh dapat menyiapkan media yang tepat seperti leaflet dan flipchart sehingga dapat membantu sasaran untuk lebih mudah mengerti. Berdasarkan penelitian pendidikan kesehatan yang langsung diberikan pada keluarga meningkatkan pengetahuan keluarga dalam merawat penderita stroke di rumah sehingga dapat meningkatkan kualitas hidup pasien stroke dan mengurangi beban bagi keluarga itu sendiri (Masraini, 2014).

\section{Metode}

Desain penelitian yang akan digunakan pada penelitian ini adalah Pre Experiment Design, dengan pendekatan One Group Pre-test-Post-test Design yaitu suatu penelitian yang dilakukan pada suatu kelompok yang diberi perlakuan/intervensi pendidikan kesehatan dengan metode penyuluhan yang dinilai sebelum intervensi dan sesudah intervensi. Selanjutnya dibandingkan hasil pre dan post test-nya. 
Bentuk rancangan ini adalah sebagai berikut :

\begin{tabular}{|c|c|c|c|}
\hline $\begin{array}{c}\text { Subjek } \\
\text { penelitian }\end{array}$ & Pre test & $\begin{array}{l}\text { Intervensi/perlakuan } \\
\text { (pendidikan kesehatan) }\end{array}$ & Post test \\
\hline Subjek & Pre & Perlakuan & Post \\
\hline $\mathrm{K}$ & 0 & I & 01 \\
\hline & Waktu 1 & Waktu 2 & Waktu 3 \\
\hline
\end{tabular}

Gambar 1. Rancangan Penelitian

Ket : $\mathrm{K}=$ Keluarga Pasien Stroke

I = Intervensi pendidikan kesehatan metode penyuluhan

0 = Penilaian awal atau pre-test sebelum intervensi

01 = Penilaian akhir atau post-test setelah intervensi

Pengambilan sampel pada penelitian ini menggunakan nonprobability sampling, dengan pendekatan consecutive sampling. Consecutive sampling adalah suatu pemilihan sampel yang dilakukan dengan memilih semua individu yang ditemui dan memenuhi kriteria pemilihan, sampai jumlah sampel yang diinginkan terpenuhi. Sampel yang diteliti adalah keluarga pasien stroke yang berada di Poli Neurologi Rumah Sakit Stella Maris Makassar yang berjumlah 60 orang, dengan kriteria sebagai berikut:

Pengumpulan data pada penelitian ini baik variabel independen maupun variabel dependen dilakukan dengan menggunakan kuisioner secara langsung kepada responden. Kuesioner yang diberikan adalah kuesioner mengenai pengetahuan keluarga tentang perawatan pasien stroke di rumah, yang diberikan sebelum melakukan pendidikan kesehatan dan setelah melakukan pendidikan kesehatan.

Jumlah penyataan pada kuesioner sebanyak 20 item, Isi pernyataan kuesioner sebelum dan sesudah sama. Leafleat sebagai media pendukung penjelasan pendidikan kesehatan. Analisis data univariat untuk menggambarkan tingkat pengetahuan keluarga sebelum dan sesudah Pendidikan Kesehatan. Analisis bivariat menggunakan uji statistik Wilcoxon, dengan tingkat kemaknaan $\alpha=0,05$.

\section{Hasil dan Pembahasan}

Tabel 1 Hasil Uji Wilcoxon Pengetahuan Responden Sebelum Dan Setelah Dilakukan Pendidikan Kesehatan

\begin{tabular}{|c|c|c|c|c|c|}
\hline & & & $\mathrm{N}$ & $\begin{array}{l}\text { Mean } \\
\text { Rank }\end{array}$ & $\begin{array}{l}\text { Sum of } \\
\text { Ranks }\end{array}$ \\
\hline \multirow{6}{*}{$\begin{array}{l}\text { Post } \\
\text { Pendidikan } \\
\text { Pre } \\
\text { Pendidikan }\end{array}$} & \multirow{3}{*}{ Kesehatan - } & Negative & $0^{\mathrm{a}}$ & .00 & .00 \\
\hline & & Ranks & & & \\
\hline & & Positive & $49^{b}$ & 25.00 & 1225.00 \\
\hline & \multirow[t]{3}{*}{ Kesehatan } & Ranks & & & \\
\hline & & Ties & $11^{\mathrm{c}}$ & & \\
\hline & & Total & 60 & & \\
\hline \multicolumn{2}{|c|}{ Asymp.Sig.(2-tailed) } & & & & .000 \\
\hline
\end{tabular}

Sumber: data primer

Dalam penelitian ini, analisa bivariat dilakukan untuk melihat bagaimana pengaruh pendidikan kesehatan tentang perawatan pasien stroke di rumah terhadap pengetahuan keluarga. Data selanjutnya dianalisis dengan menggunakan uji wilcoxon dan didapatkan 
hasil pada uji statistic dengan nilai $\mathrm{p}<0,000$. Hal ini menunjukkan bahwa $\mathrm{p}<\mathrm{a}$ yang berarti Ho ditolak dan Ha diterima, maka dapat disimpulkan bahwa ada pengaruh pendidikan kesehatan tentang perawatan pasien stroke di rumah terhadap tingkat pengetahuan keluarga.

Dari hasil uji didapatkan data sebelum dilakukan pre pendidikan kesehatan terdapat 12 responden yang memiliki pengetahuan kurang, 17 responden memiliki pengetahuan cukup, 20 responden memiliki pengetahuan baik, dan 11 responden memiliki pengetahuan sangat baik, tetapi setelah dilakukan pendidikan kesehatan didapatkan hasil tidak ada responden yang memiliki pengetahuan kurang, 13 responden memiliki pengetahuan cukup, 27 responden memiliki pengetahuan baik dan 20 responden memiliki pengetahuan sangat baik. Berdasarkan hasil uji wilcoxon, terdapat 49 responden mengalami peningkatan pengetahuan setelah diberikan pendidikan kesehatan.

Hasil penelitian menunjukkan ada 11 responden yang memiliki tingkat pengetahuan sebelum dan sesudah diberikan pendidikan kesehatan tidak mengalami perubahan. Ada beberapa faktor lain yang mempengaruhi perubahan pengetahuan, meskipun responden telah diberikan pendidikan kesehatan, antara lain;

1. Umur. Sebagian besar responden pada penelitian ini berada pada umur 31 tahun ke atas, bahkan sebanyak 35 persen di atas 43 tahun. Hal ini mungkin mempengaruhi daya tangkap terhadap suatu stimulus.

2. Pengalaman dan sumber informasi. Berdasarkan hasil wawancara beberapa reponden didapatkan bahwa mereka tidak memiliki pengalaman sama sekali dalam merawat pasien stroke. Demikian juga tidak adanya sumber informasi yang pernah mereka dapatkan terkait perawatan pasien stroke, baik dari petugas Kesehatan atau perorangan maupun dari media elektronik ataupun cetak.

Kedua faktor di atas ditambah dengan faktor sosial ekonomi sejalan dengan pernyataan Kusumawardani, (2010) yang menyatakan bahwa, semakin cukup umur, tingkat kematangan, dan kekuatan seseorang akan lebih matang dalam berpikir dan bekerja. Hal yang senada juga disebut Hidayat (2006), perubahan perilaku/peran dapat disebabkan oleh proses pendewasaan melalui pengalaman umur, individu yang bersangkutan, telah melakukan adaptasi terhadap lingkungan.

Selain itu dapat dilihat bahwa Sebagian besar responden mengalami perubahan pengetahuan setelah diberikan Pendidikan Kesehatan. Menurut Mubarak (2007) salah satu factor yang mepengaruhi penerimaan seseorang terhadap suatu stimulus atau perubahan pengetahuan salah satunya dipengaruhi oleh factor minat. Berdasarkan hasil pengamatan dan wawancara peneliti didapatkan bahwa responden ini memiliki keinginan dan minat besar untuk dapat mempelajari dan menerapkan metode perawatan pasien stroke ini. Mereka akan lebih senang jika dapat melakukan perawatan pada keluarga yang stroke secara mandiri di rumah masing. Hal ini selain lebih santai, mereka juga dapat mengurangi pengeluaran biaya perawatan di Rumah Sakit. Menurut peneliti hal ini sejalan dengan data bahwa Sebagian besar mereka adalah ibu rumah tangga dan karyawan dari pabrik dengan penghasilan yang mungkin hanya cukup untuk memenuhi kebutuhan hidup sehari-hari. Hal ini yang mendorong mereka menyimak dengan baik Pendidikan Kesehatan yang diberikan oleh tim peneliti saat penelitian ini berlangsung. 


\section{Simpulan dan Saran}

Berdasarkan hasil kesimpulan penelitian yang telah dilakukan; ada pengaruh pendidikan kesehatan tentang perawatan pasien stroke di rumah terhadap tingkat pengetahuan keluarga.

Dengan hasil penelitian ini diharapkan, tingkat pengetahuan keluarga semakin bertambah setelah diberikan pendidikan kesehatan dan mampu mengaplikasikan perawatan pasien stroke dalam kehidupan sehari-hari. Dengan penelitian ini diharapkan menjadi pedoman Satuan Operasional Prosedural (SOP) untuk rumah sakit sehingga perawat mampu menerapkan discharge planning pada keluarga mengenai perawatan pasien stroke sehingga tingkat pengetahuan keluarga semakin bertambah.

\section{Daftar Rujukan}

Adientya , Gabriella., Handayani Fitria.,(2012). Stres Pada Kejadian Stroke. Fakultas kedokteran Diponogoro. jurnal nursing studies, volume 1, nomor 1 tahun 2012, halaman $183-188$

Agustina.R.E. Eka.(2009) Prevalensi stroke iskemik pada pasien rawat inap di RSUP Fatmawati Jakarta Selatan. Program studi pendidikan dokter fakultas kedokteran dan ilmu kesehatan universitas islam negeri syarif hidayatullah, Jakarta.

American Heart Association. 2010. Stroke Risk Factor.

(http://ww.strokeassociation.org/presenter.jhtml identifier). Diakses tanggal 28 November 2015

Ardila, Ayu (2014).Hubungan Hipertensi Tidak Terkontrol Dengan Stroke Berulang.Surakarta :Fakultas Kedokteran

(http://eprints.ums. ac.id/28056/22/naskah_publikasi.pdf) Diakses pada tanggal 14 Februari 2016

Barbara Voetsch et. al. (2012). Paraoxonase 192 GlnArg Polymorphism :An Independent Risk Factor for Nonfatal Arterial Ischemic Stroke Among Young Adults. American Heart Association:(http://stroke.ahajournals. org/content/33/6/1459) Diakses pada 01 Desember 2015

Dewi, S.P.,(2010).Hubungan peran serta keluarga dalam perawatan stroke dengan tingkat depresi pada penderita pasca stroke di rumah sakit umum daerah dr. moewardi surakarta. Fakultas Ilmu Kesehatan Universitas Muhammadiyah Surakarta (http://eprints.ums.ac.id/ 9451/1/J210050087.pdf) di akses pada tanggal 13 Februari 2016

Hidayah, Karuniawati., (2015) Secondary prevention to reduce the occurrence of recurrent stroke onischemic stroke. .Fakultas Farmasi, Unversitas Gadjah Mada, Yogyakarta: Volume 5 Nomor 1 - Maret 2015

Herawaty, Ikayusi.,(2009).Penatalaksanaan Terapi Latihan Pada Pasien Paska Stroke Hemorage Dextra Stadium Recovery. Universitas Muhammadiyah Surakarta.(http://eprints.ums.ac.id/ 6637/1/J10006 0059 .pdf). Di akses pada tanggal 15 Desember 2015

Karuniawati, Hidayah.,(2016).Profil penggunaan terapi pencegahan sekunder pada pasien stroke iskemik. Fakultas Farmasi Universitas Muhammadiyah, Surakarta.

Masraini N.D:,(2014). Pengalaman Keluarga sebagai Caregiver dalam Merawat Pasien Stroke di Rumah. Fakultas Keperawatan Universitas Sumatera Utara

Misbach, Jusuf.,(2011).Stroke :Aspek Diagnostik, Patofisiologi, Manajemen.Jakarta : FKUI

Munawwar , Irmawati. (2011).Faktor risiko kejadian str oke pada pasien rawat inap RSUP dr.Wahidin SudirohusodoM Makassar(http://repository. unhas.ac.id: 4001 
/digilib/files /disk1/78/ --irmawatimu-3899-1-skiripsi-p.pdf) dia kses pada tanggal 20 Februari 2016

Nastiti, Dian.,(2012).Gambaran faktor resiko kejadian stroke pada pasien stroke di rumah sakit rawat inap Krakatau Medika.FKM.UI, Depok

Notoatmodjo S. (2010). Metodologi Penelitian Kesehatan.Jakarta : Rineka Cipta

Oktariani. 2011. Hubungan Antara Tingkat Pengetahuan Klien tentang Stroke dengan Konsep Diri Di Poliklinik Syaraf RSU PKU Muhammadiyah Yogyakarta. Jurnal Keperawatan. Vol 2 No. 1, Januari 2011 (1-8). http://ejournal-s1.undip.ac.id/index.php/jnursing diakses 12 Desember 2015

Pska, K et. al. 2007. Risk faktors for acute ischaemic stroke in young adults in South India. J Neurol Neurosurg Psychiatry 2007; 78: 959-963.

(Downloaded from jnnp.bmj.com on Desember 10, 2015 Published by group.bmj.com)

Rahmi, upik.,(2014). Pengaruh Discharge planning terstruktur terhadap kualitas hidup pasien stroke.Depok.Fakultas ilmu keperawatan , UI.

Raski, I. R.(2014).Profil faktor risiko yang dapat dimodifikasi pada kasus

Stroke berulang di rsud arifin achmad Provinsi Riau.

(http://www.google.com/jom.unri.ac.id/index.php/JOMFDOK/article/download/2871/2 785)

Ratnasari, Nining.,(2014).Gambaran keluarga dalam memutuskan tindakan kesehatan pada keluarga dengan serangan stroke berulang di Wilayah Kerja Puskesmas Puput Cipuput Timur. (http://eprints.ump. ac.id/9451/1/J21005 0087 .pdf) di akses pada tanggal 18 Februari 2016

Riskesdas. 2013. Prevalensi Penyakit Stroke Tahun 2007 dan 2013. Diakses Tanggal 10 Novenber 2015

Safitri, F. Nur.(2012).Resiko stroke berulang dan pengetahuan hubungannya dengan pengetahuan dan sikap keluarga . Fakultas Ilmu Keperawatan Universitas Padjadjaran (http://jurnal.unpad. ac.id/ejournal /article/viewFile/679/725).

Siswanto, Yuliaji.(2005). Beberapa faktor yang mempengaruhi stroke berulang. Universitas Diponogoro, Semarang.

(http://eprints. undip.ac.id/ 14537/1/2005MEP4288.pdf_)

Skandar, Juniadi.(2011).Stroke Waspadai dan Ancaman. Yogyakarta : CV Andi.

Sonatha, Bety.,( 2012). Hubungan Tingkat Pengetahuan Dengan Sikap Keluarga Dalam Pemberian Perawatan Pasien Pasca Stroke. Depok. Fakultas Keperawatan, UI.

Sopiyudin M.,Dahlan.,(2010). Langkah-Langkah Membuat Proposal Penelitian Bidang Kedokteran dan Kesehatan.Jakarta : CV Sagung Seto.

Sulami, Sri., prastiani dwi, dkk.(2012). Hubungan Dukungan Emosional Keluarga Dengan Kepatuhan Kunjungan Ulang Pasien Stroke Di Poliklinik Saraf Rsud Dokter Soeselo Kabupaten Tegal. Jurusan Keperawatan, STIKES Bhakti Mandala Husada Slawi, Tegal

Susanto, Tuntut.,(2012).Buku ajar Keperawatan Keluarga : aplikasi teori pada praktik keperawatan keluarga.Jakarta : CV. Trans Info Media

Sofyan, M.Aisyah.,(2012). Hubungan Umur, Jenis Kelamin, dan Hipertensi dengan Kejadian Stroke.FK UHO.

Ursin, Irwana., (2011 ).Pengaruh Hipertensi Terhadap Kejadian Stroke Iskemik Dan Stroke Hemoragik Di Ruang Neurologi Di Rumah Sakit Stroke Nasional (Rssn) Bukittinggi . FKM, USU.

Wawan A dan Dewi M. (2010). Teori dan Pengukuran Pengetahuan, Sikap dan Perilaku Manusia. Yogyakarta : Nuha Medika 